\title{
Applying Oncology Formulary and Benefit Design Innovations to the Management of Multiple Myeloma in the Managed Care Setting
}

\author{
C. Daniel Mullins, PhD, and Jeffrey D. Dunn, PharmD, MBA
}

T here has been a marked increase in the number of treatments for multiple myeloma over the past 10 years. New drugs such as thalidomide, lenalidomide, and bortezomib have been shown to be active in multiple myeloma and are often combined with older agents such as melphalan to create potent treatment regimens (Table 1). ${ }^{1}$ Although the development of these drugs provides patients with several new therapeutic alternatives, clinicians are now challenged to choose between several competing interventions when devising the safest and most effective management strategy for each patient. Health care policy makers, health plan administrators, payers, and patients are also challenged to select the therapy that provides the greatest value for their investment. Issues such as "off-label" use of drug therapies and data gaps, as well as potential solutions, such as comparative effectiveness research (CER), patient-centered health care delivery, and oncology drug benefit design, are discussed.

\section{Off-Label Drug Use in Oncology}

Decisions regarding patient management should be evidence based, yet more than half of the treatments received by patients are administered without clear evidence of clinical efficacy. ${ }^{2}$ This is a particular challenge in oncology, an area in which many drug therapies are used outside their labeled indications. A survey of 3,500 office-based oncology practices identified at least 87 distinct oral anticancer therapies used offlabel. ${ }^{3}$ Similarly, the National Comprehensive Cancer Network (NCCN) estimates that as many as $75 \%$ of all cancer drugs are used outside the scope of their specific approval. ${ }^{4}$ In multiple myeloma, oncologists frequently prescribe lenalidomide as first-line therapy. Although there are studies supporting the use of lenalidomide as a first-line therapy, it is only approved by the U.S Food and Drug Administration (FDA) for use in combination with dexamethasone for patients with multiple myeloma who have had at least one prior treatment. ${ }^{5}$

Several reasons have been put forward to explain why offlabel use is so widespread in oncology. Oncologists frequently discover through clinical practice that different types of cancer share a common biology and thus sensitivity to a particular therapy. In such cases, off-label use can become widespread and possibly the standard of care without the support of a labeled indication. ${ }^{6}$ For some drugs, clinical trial data to support the use of the product outside the labeled indication are never generated, possibly because of the expense of pursuing a label expansion; in particular, once a drug nears the end of its patent life, manufacturers have little incentive to invest addi- tional resources in the product. ${ }^{7}$ There is also the possibility that the product is never tested in novel disease types because of concerns that it may be inferior or equivocal to current care. ${ }^{8}$

\section{Data Gaps}

Regardless of why therapies are used off-label, a common denominator for many drugs used to treat multiple myeloma is the lack of clinical trial data that directly compare one treatment with another. ${ }^{9}$ The scarcity of comparative data not only makes it difficult for providers and patients to select the most appropriate therapy but also for plan administrators and payers to fully evaluate products for possible inclusion or preference in the health plan benefit. In addition, the paucity of evidence hinders public health policy makers in their efforts to assess the overall value of oncology therapies. A systematic review of the 4 compendia approved to provide the Centers for Medicare $\&$ Medicaid Services with guidance on oncology treatments, including multiple myeloma, noted that each compendium lacked current evidence and transparency on how the therapies included in the document were selected. ${ }^{8}$

\section{Trial Endpoints}

As discussed by Huff and Dunn in "Identifying Indicators of Outcomes and Implementing Treatment Pathways" (p. S5), overall survival (OS) is considered the most reliable cancer endpoint because, among other qualities, it is both precise and easy to measure. ${ }^{10}$ However, the cost and time required to measure OS has led to the use of endpoints that act as surrogates or indicators of expected clinical efficacy. ${ }^{11}$ For some tumor types, response of the surrogate marker is predictive of an OS benefit-an outcome subsequently confirmed on further investigation-but this is not always the case. ${ }^{12}$ In multiple myeloma trials, complete response is often the targeted endpoint; however, trial data may not be sufficiently robust to definitively indicate that the directional change in complete response is predictive of prolonged OS. ${ }^{13}$ This lack of confidence in trial endpoints creates challenges when designing the pharmacy benefit and for therapeutic decision making.

Patient-reported outcome (PRO) measures provide validated evidence of response to therapy from the patient's point of view and may reflect underlying health status more accurately than clinician reporting. ${ }^{14} \mathrm{PROs}$ are increasingly recognized as important for treatment and/or diseaserelated consequences that are directly experienced by patients, such as symptoms and health-related quality of life. Most phase 3 multiple myeloma trials fail to include well-designed 


\begin{tabular}{|c|c|c|c|}
\hline Drug & $\begin{array}{l}\text { Trade } \\
\text { Name }\end{array}$ & $\begin{array}{c}\text { FDA } \\
\text { Approval } \\
\text { Date }\end{array}$ & Indication \\
\hline Melphalan 54 & Alkeran & 1962 & $\begin{array}{l}\text { Palliative treatment of patients } \\
\text { with multiple myeloma }\end{array}$ \\
\hline Bortezomib $^{55}$ & Velcade & $\begin{array}{l}\text { May } \\
2003\end{array}$ & $\begin{array}{l}\text { Patients with relapsed multiple } \\
\text { myeloma }\end{array}$ \\
\hline Thalidomide 56 & Thalomid & $\begin{array}{l}\text { May } \\
2006\end{array}$ & $\begin{array}{l}\text { In combination with } \\
\text { dexamethasone for the treatment } \\
\text { of patients with newly diagnosed } \\
\text { multiple myeloma }\end{array}$ \\
\hline Lenalidomide $^{5}$ & Revlimid & $\begin{array}{l}\text { June } \\
2006\end{array}$ & $\begin{array}{l}\text { In combination with } \\
\text { dexamethasone for the treatment } \\
\text { of multiple myeloma in patients } \\
\text { who have received at least } 1 \\
\text { prior therapy }\end{array}$ \\
\hline $\begin{array}{l}\text { Pegylated } \\
\text { liposomal } \\
\text { doxorubicin } 57\end{array}$ & Doxil & $\begin{array}{l}\text { May } \\
2007\end{array}$ & $\begin{array}{l}\text { In combination with bortezomib } \\
\text { in patients who have not } \\
\text { previously received bortezomib } \\
\text { and have received at least } 1 \text { prior } \\
\text { therapy }\end{array}$ \\
\hline Bortezomib $^{55}$ & Velcade & $\begin{array}{l}\text { June } \\
2008\end{array}$ & $\begin{array}{l}\text { Patients with newly diagnosed } \\
\text { multiple myeloma }\end{array}$ \\
\hline
\end{tabular}

quality-of-life studies that can shed light on how patients in different risk categories benefit from various interventions. ${ }^{13}$ This may be changing, however, because several major regulatory and advisory entities, including the $\mathrm{FDA}^{14}$ and Patient-Centered Outcomes Research Institute (PCORI), ${ }^{15}$ are emphasizing the importance of incorporating PROs into cancer research and health care policy.

\section{Comparison of Treatment Alternatives}

Ideally, robustly designed randomized controlled clinical trials (RCTs) would simultaneously compare all interventions of interest. Unfortunately, such studies are almost never available because new drugs are often compared with placebo or standard care but seldom with each other because manufacturers have little incentive to conduct exhaustive comparative trials-their goal is to achieve regulatory approval as quickly as possible. ${ }^{16-18}$ Additionally, RCTs are seldom designed to answer pragmatic questions about the use of a new therapy in the context of existing treatment options or in patients who do not meet the inclusion criteria of the RCT.

Despite the lack of head-to-head trials, it is still necessary to compare the effectiveness of competing treatment alternatives to answer relevant policy questions. ${ }^{18}$ With relevant RCT-based comparisons lacking, indirect comparisons generated by decision analytic modeling tools are increasingly used to guide decision making. An indirect treatment comparison assesses the relative value of treatments that have never been directly
TABLE 2 Data Sources Used to Conduct Comparative Effectiveness Research

Primary Comparative Effectiveness Research

- Systematic reviews of existing research, including meta-analysis

- Decision modeling, with or without cost information

Secondary Comparative Effectiveness Research

- Retrospective analysis of existing clinical or administrative data, including "natural experiments"

- Prospective observational studies, including registries, that observe patterns of care and treatment outcomes; patients in these studies are not assigned to specific groups

- Experimental studies, including randomized clinical trials, in which patients or groups of patients are assigned to alternative treatments, practices, or policies

Adapted from: Tunis SR, Benner J, McClellan M. Comparative effectiveness research: policy context, methods development and research infrastructure. ${ }^{22}$

compared but have been compared with a common comparator. For example, if regimen $A$ has been compared with B, and $B$ has been compared with $C$ in randomized trials, indirect comparisons can provide insights on the relative effectiveness of A versus $\mathrm{C} .{ }^{17}$ More complex modeling allows comparison of 4 or more interventions that have never been compared directly, providing decision makers with a powerful tool to evaluate competing treatment alternatives. Despite this utility, indirect comparisons make important assumptions about the stability of relative treatment effects across trials that are easily violated. Thus, in the absence of (head-to-head) RCTs, decision makers can use indirectly generated evidence as long as they are aware of the potential risks in using evidence of lower quality and that the potential benefits outweigh these risks. ${ }^{19}$

\section{Comparative Effectiveness Research}

CER involves assessment of a medical intervention against alternative interventions with the goal of identifying treatment approaches that are most likely to have preferable benefit-risk profiles or are considered cost-effective in real-world clinical settings. ${ }^{2}$ CER results are intended to be relevant to a broad array of individuals who represent the wide variety of patients in the real world. ${ }^{20}$ They can also be used to assist providers, payers, and patients in making informed health care decisions. Conducted in the United States since the 1970s, CER efforts recently received a significant boost in funding with the American Recovery and Reinvestment Act of 2009, with the additional funding earmarked for expansion of the infrastructure (e.g., databases, electronic health records, patient registries) and research (e.g., development of methodological best practices) necessary to assess the relative strengths and weaknesses of medical interventions. ${ }^{21,22} \mathrm{CER}$ has been the basis for health care decision making for several years in several other countries, most notably the United Kingdom. ${ }^{23}$ 


\section{CER and Data Analysis}

CER uses data from numerous sources (Table 2) to analyze the relative value of different interventions. ${ }^{22}$ "Primary" CER relies on systematic reviews of existing research, including meta-analysis, and decision modeling to establish a conclusion, whereas "secondary" CER uses retrospective analysis of clinical databases, prospective observational studies, and experimental studies, including randomized trials. ${ }^{22}$

CER-based health care decision making requires comparisons of all relevant competing interventions. In reality, such studies rarely exist, so CER frequently relies on indirect treatment comparisons and network meta-analysis to provide useful evidence to guide selection of the best choice of treatment. ${ }^{19}$ The treatment with the greatest relative effect versus the common comparator is considered to be superior. ${ }^{24-26}$ CER also generates data using network meta-analyses. In contrast to a traditional meta-analysis, which includes only studies that compare the same intervention with the same comparator, a network meta-analysis includes multiple pairwise comparisons across a range of interventions. ${ }^{27}$ Thus, a network metaanalysis provides estimates of the relative treatment effect on multiple treatment comparisons for comparative effectiveness purposes. ${ }^{27}$ Mixed-treatment comparisons, a special case of network meta-analysis, combine direct and indirect evidence for particular pairwise comparisons, thereby synthesizing a greater share of the available evidence than a traditional metaanalysis. ${ }^{19}$

Both direct and indirect evidence contribute to the total body of evidence. ${ }^{16}$ Even when the results of the direct evidence are conclusive, combining them with the results of indirect estimates may yield a more precise estimate of the interventions directly compared and broaden inference to the population sampled because it links and maximizes existing information within the entire scope of treatment comparisons. ${ }^{25}$

\section{Application to the Prescribing Community}

Use of the rigorous statistical analysis inherent to CER is accompanied by the risk that translation of the findings to the prescribing community, payers, and patients is lost in the complexity of the methodology used to generate the results. ${ }^{28}$ In the real world, a trade-off occurs between the complexity of the methodology used to generate robust comparisons and ensuring the data generated are applicable and understandable to those stakeholders who require information to make decisions about benefit design, clinical pathways, formularies, and treatment decisions. Having patients, providers, health plan managers, and other decision makers participate in the design of comparative effectiveness studies can ensure that this research focuses on the evidence gaps most relevant to the parties who will be most impacted by its results. ${ }^{28}$

\section{TABLE 3 Features of Patient-Centered Outcomes Research}

- Assesses the benefits and harms of preventive, diagnostic, therapeutic, palliative, or health delivery system interventions to inform decision making, highlighting comparisons and outcomes that matter to people

- Is inclusive of an individual's preferences, autonomy, and needs, focusing on outcomes that people notice and care about such as survival, function, symptoms, and health-related quality of life

- Incorporates a wide variety of settings and diversity of participants to address individual differences and barriers to implementation and dissemination

- Investigates (or may investigate) optimizing outcomes while addressing burden to individuals, availability of services, technology, and personnel and other stakeholder perspectives

Adapted from: Patient-Centered Outcomes Research Institute. Patient-centered outcomes research. ${ }^{29}$

\section{Patient-Centered Health Care Delivery}

\section{Patients as Key Stakeholders in Health Care}

The role of the patient in the health care decision-making process has recently risen to prominence. ${ }^{29,30}$ Patients are increasingly regarded as one of the key stakeholder groups that, alongside regulators, payers, and clinicians, influence access to and reimbursement for drug therapies. Recognition of the importance of the patient perspective is reflected by the creation of the Patient-Centered Outcomes Research Institute (PCORI) under the U.S. Patient Protection and Affordable Care Act. ${ }^{29}$ PCORI was created to conduct research to provide information about the best available evidence to help patients and their providers make more informed decisions. PCORI is charged with conducting outcomes research designed to answer specific patient-focused questions about the benefits and harms of preventive, diagnostic, therapeutic, or delivery system interventions. PCORI addresses one of the primary concerns regarding health care in the United States: In many cases, patients and their families, caregivers, and even their health care providers do not have the information they need to make choices aligned with their desired health outcomes..$^{30}$ Outcomes of interest to PCORI include survival, function, symptoms, and healthrelated quality of life ${ }^{30}$ (Table 3 ).

When patients have information, it allows them to have informed conversations with their medical oncologists and other providers about treatment strategies and therapeutic selection. If the patient has access to evidence indicating a particular therapy is beneficial, both the patient and provider may be more confident that spending limited health care resources on the therapy is a wise investment. The pharmaceutical industry also has an interest in patient-centered research because it is not to their advantage when the wrong patient receives the wrong therapy and experiences toxicities and adverse events. 
Payers also benefit when the data used for benefit design include the perspective of the patient, particularly because patients are often asked to shoulder a significant burden of the drug cost through copayments and other cost-sharing structures. ${ }^{31}$

\section{Applying a Patient-Centered Approach to Multiple Myeloma}

Patient-centered data on multiple myeloma treatment are currently lacking. Some of the challenges stem from a lack of health literacy on the part of the patient. ${ }^{32}$ Others result from provider-related limitations such as a lack of time to explain complex information and a lack of tools to facilitate treatment planning, as well as insensitivity to patients' informational, cultural, and emotional needs. ${ }^{32}$ These challenges are compounded by difficulties in generating evidence utilizing CER techniques. Despite a growing number of treatments, there is limited evidence from new trials that allow generation of indirect treatment comparisons. In essence, there is a need for more real-world evidence outside of phase 3 clinical trials to inform value decisions.

For patient-centered research to be truly valuable, patients need to know how the evidence applies to them individually in terms of survival, toxicities, and cost..$^{29,30}$ For example, knowledge that a drug increases progression-free survival and disease-free survival is helpful for regulatory approval, but what does this mean in terms of the likelihood of an individual patient surviving for another 3 or 5 years? How does the drug toxicity profile reported in the trial apply to a patient who may fall outside the inclusion criteria used in the study? Ultimately, data are needed so a patient can get answers to questions such as, "Given my characteristics as a patient with multiple myeloma and given my personal preferences in terms of trade-off for toxicities and extension of life, what therapy will provide me the best value for my money?" To answer these and similar questions, PCORI will conduct outcomes research assessing the benefits and harms of preventive, diagnostic, therapeutic, or health care delivery system interventions, highlighting comparisons and outcomes relevant to patients and their caregivers. ${ }^{30}$

\section{Cancer Drugs and Pharmacy Benefit Design}

Spending on cancer drugs has risen faster than spending in many other areas of health care. Currently, sales of anticancer drugs are second only to those of drugs for heart disease, and $70 \%$ of these sales come from products introduced in the past 10 years. ${ }^{33}$ In 2010, cancer treatments made up approximately $15 \%$ of total specialty pharmacy spending. ${ }^{34}$ Most new therapies cost at least $\$ 5,000$ per month, ${ }^{35}$ and cost-effectiveness ratios of many of these products can exceed commonly accepted thresholds, typically between $\$ 140,000$ and $\$ 200,000$ per quality-adjusted life year. ${ }^{36}$

Although cancer drugs have been traditionally viewed as "off limits" for utilization management strategies, the steady upward rise in cancer drug spending has triggered a vigorous debate about the overall value of oncology treatments in terms of clinical, pharmacoeconomic, humanistic, and societal endpoints. ${ }^{33,36}$ Payers are now motivated to apply payment reforms and quality measurements to cancer and approach the category like other chronic disease states. ${ }^{37}$ However, a lack of good empirical evidence hinders attempts to manage oncology products. ${ }^{38}$ Consequently, there is no standard to the oncology benefit design in the marketplace and most plans place specialty oncology drugs into the existing benefit and attempt to manage them using traditional utilization limits and cost controls.

\section{Design Considerations}

Although a standard oncology drug benefit has yet to emerge, several concepts are being implemented as plan administrators attempt to determine the overall value of treatments. Clinical practice guidelines from the NCCN and the American Society of Clinical Oncology serve as standards of medical care and as compendia for reimbursement for approved and for offlabel uses of cancer drugs. ${ }^{4}$ There have been recent efforts to minimize variation in care through defining limited treatment pathways. Several managed care organizations now offer pathway programs that identify "preferred" options: either a single-treatment option per condition or a subset of treatment options per condition. These programs are often developed in a specific health plan market in collaboration with participating oncologists. Oncologists who achieve a specified level of pathway compliance may receive additional compensation..$^{39}$ Use of preferred pathways can also help drive utilization of specific drug products and therefore possibly maximize manufacturer rebates, further lowering net costs to payers. Plan members can be encouraged to utilize drugs identified with the preferred pathway, with lower out-of-pocket costs for preferred or generic agents. ${ }^{40}$

In the past, traditional cancer treatment (i.e., chemotherapy) was primarily delivered intravenously or by injection, but orally administered drugs have become the standard of care for many types of cancer. Current pharmacotherapy for multiple myeloma includes 4 targeted therapies: 2 self-injectable agents and 2 orally administered drugs (the 2 orally administered therapies do not have intravenous or injectable equivalents). ${ }^{1}$ Oral cancer drugs, including those for multiple myeloma, have historically been covered under the pharmacy benefit, which often means higher coinsurance or cost-sharing burden for patients, whereas injectable agents have been covered by the medical benefit, with fewer out-of-pocket costs. ${ }^{41}$ This convention is now changing, with many managed care organizations moving cancer drugs to the pharmacy benefit rather than the medical benefit; this is where high-cost drugs for multiple myeloma and other cancers are sometimes placed in a "higher tier," so that instead of having a specified copayment, 
the patient is responsible for paying up to $50 \%$ coinsurance. Although the intent is to reduce the payer's financial risk, this approach makes these drugs unaffordable for many patients. ${ }^{39}$

Cancer drugs have historically been insensitive to cost sharing, ${ }^{42}$ but as new and more expensive therapies become available, patients are facing a steady escalation of out-of-pocket costs for cancer treatments-in some cases exceeding $\$ 35,000$ per year., ${ }^{43}$ In other therapeutic areas, high out-of-pocket expenses negatively affect patient adherence, ${ }^{44}$ but currently there is little evidence in oncology to suggest that increased cost sharing results in poor outcomes. However, with efforts to increase patient awareness of the value of oncology therapies under way, it is feasible that patients may balk at paying a premium for cancer therapeutics that achieve only marginal benefits.

Data are crucial to the successful management of the oncology drug benefit because timely access to reliable data allows administrators to assess plan performance and adjust the benefit as trends arise..$^{45}$ In many practice settings, the electronic medical record system allows for the collection of pharmacy data originating at the point of care. ${ }^{46}$ However, reliable data are not always available in some cases, especially under the medical benefit, where the timing of adjudication is often not synchronized with the pharmacy plan and consequently not reported as part of the National Council for Prescription Drug Programs performance report. ${ }^{46}$ Lack of an integrated medical and pharmacy drug benefit may hinder the ability of pharmacy managers to capture and process claims originating in the medical benefit. Data on the total cost of care, including total cost, indirect cost, medical offsets, and cost of adverse effects, may also be lacking and therefore limit the ability to consider these inputs when making benefit design decisions. Further, cancer drugs covered in the medical benefit are often not tiered, resulting in similar copayments or cost-sharing amounts for all products and making it more difficult to provide incentives to physicians and patients for use of preferred products.

\section{Value-Based Benefit Design}

A value-based benefit design uses plan-based incentives to encourage patients to appropriately use recommended treatment pathways and engage in healthy behaviors to improve health outcomes and control or reduce costs. ${ }^{47}$ A plan-based incentive may include reduction or elimination of patient cost sharing for services that show strong evidence of clinical benefit. Alternatively, patients may incur increased cost sharing if services that do not show evidence of clinical benefit are used. The most commonly implemented value-based benefit programs lower copayments on classes of medications identified as high value. For example, the program run by Pitney Bowes provides asthma and diabetes medications to its employees for free, and the company reported a 19\% decrease in costs per asthmatic patient. ${ }^{48}$ Value-based benefit designs are intended to focus on the long term. This approach may initially increase the cost of care in pursuit of quality enhancements and hence should not be considered a strict cost-saving strategy. Rather, value-based benefit design is a means to increase value for the health care dollar. ${ }^{49}$

Although a value-based benefit has been implemented by several payers and employer groups to manage chronic conditions such as diabetes ${ }^{48,50}$ and hypercholesterolemia, ${ }^{51}$ it is currently unclear if use of such a benefit results in improved health outcomes and controls or reduces health care costs. There may be a good fit for value-based design in the specialty oncology category due to the high cost of therapies used to treat a disease, with significant downstream costs and lower numbers of patients with the disease. If value-based design is integrated with other value-producing initiatives, such as CER, there is potential to lower costs for patients and health plans as well as improve treatment outcomes.

\section{Accountable Care Organizations}

The U.S. health care system remains fragmented; no single group of participants-physicians, hospitals, public or private payers, or employers-takes full responsibility for guiding the health of a patient or community; care is distributed across many sites; and integration among them may be deficient..$^{52}$ Accountable care organizations (ACOs) were conceived as part of the health care reform legislation of $2009 .{ }^{53}$ Under the new legislation, an ACO will assume full responsibility for meeting a proposed 65 quality measures involving prevention, diagnosis, treatment, continuing management, and aftercare of chronic diseases in a population of Medicare beneficiaries for at least 3 years. ${ }^{53}$ As the legislation is currently written, oncologists and other specialists cannot start or manage an ACO, but they can join as many ACOs as they wish. In addition, of the quality measures outlined in the ACO law, only the preventive measures of screening for colon cancer and mammography relate specifically to cancer care. ${ }^{53}$

The main purpose of an ACO is to foster change in patient care so as to accelerate progress toward better care for individuals, better health for populations, and slower growth in costs through improvements in care. If an ACO succeeds in both delivering high-quality care and reducing the cost of that care to a level below what would otherwise have been expected, it will share in the Medicare savings it achieves..$^{53}$ Accountable care should not be viewed as a panacea but rather one of a number of complementary initiatives chartered by the Affordable Care Act to help achieve the 3-part goal of lower costs, improved care, and better health. ${ }^{52}$

\section{Summary}

A historical reliance on clinical trials designed to achieve regulatory approval has led to many therapeutic breakthroughs in cancer pharmacotherapy that have significant internal validity for demonstrating efficacy. However, despite significant 
advances in cancer therapeutics, treatment outcomes remain less than ideal when patients who do not meet the strict inclusion criteria identified in the clinical trial receive treatment with the drug, a problem compounded when physicians have insufficient evidence to guide personalized treatment regimens. Within the past few years, an emphasis on patientcentered research has emerged; this is an approach that not only provides data to support a formulary decision, but also one that generates data applicable to the individual patient. As the U.S. health care delivery system continues to reform and evolve, CER and patient-centered outcomes research will be used to generate the type of data required by patients to make informed decisions about how to most wisely invest their limited health care resources. CER and patient-centered outcomes will also inform the decision making of payers and plan administrators as they redesign the oncology pharmacy benefit in the face of ongoing innovation, rising utilization, and increased costs. Going forward, all new benefits must strike the appropriate balance between clinical efficacy and safety, patient expense and noncompliance, and improved treatment outcomes.

\section{Authors}

C. DANIEL MULLINS, PhD, is Professor and former Department Chair of the Pharmaceutical Health Services Research Department, University of Maryland School of Pharmacy, Baltimore, Maryland; and JEFFREY D. DUNN, PharmD, MBA, is Formulary and Contract Manager, SelectHealth, Salt Lake City, Utah.

AUTHOR CORRESPONDENCE: C. Daniel Mullins, PhD, University of Maryland School of Pharmacy, 220 Arch St., 12th Fl., Baltimore, MD 21201. Tel: 410.706.0879; Fax: 410.706.5394; E-mail:dmullins@rx.umaryland.edu.

\section{REFERENCES}

1. Anderson KC, Alsina M, Bensinger W, et al; National Comprehensive Cancer Network. Multiple myeloma. J Natl Compr Canc Netw. 2011;9(10): 1146-83.

2. Institute of Medicine. Report brief: initial national priorities for comparative effectiveness research. June 2009. Available at: http://www.iom.edu/ /media/Files/Report\%20Files/2009/ ComparativeEffectivenessResearchPriorities/CER\%20report\%20brief\%20 08-13-09.ashx. Accessed October 18, 2012

3. Goss T. Off-label use of anticancer therapies: physician prescribing trends and the impact of payer coverage policy. 2008. Gaithersburg, MD: Covance Market Access Services. Available at: http:/www.amcp.org/WorkArea/ DownloadAsset.aspx?id=11587. Accessed October 18, 2012

4. No authors listed. "Off-label" indications for oncology drug use and drug compendia: history and current status. J Oncol Pract. 2005;1(3):102-05.

5. Revlimid [lenalidomide] package insert. Celgene Corporation. 2009.
6. Pfister DG. Off-label use of oncology drugs: the need for more data and then some. J Clin Oncol. 2012;30(6):584-86.

7. Casali PG; Executive Committee of ESMO. The off-label use of drugs in oncology: a position paper by the European Society of Medical Oncology (ESMO). Ann Oncol. 2007;18(12):1923-25.

8. Abernethy AP, Raman G, Balk EM, et al. Systematic review: reliability of compendia methods for off-label oncology indications. Ann Intern Med. 2009;150(5):336-43.

9. Owens, GM. Measuring value of multiple myeloma therapies. Manag Care Oncol. 2001;3(3):10-14. Available at: http://www.managedcareoncology. com/media/416773/final\%20layout_mco\%20special\%20feature_q3-11.pdf. Accessed October 18, 2012

10. U.S. Department of Health and Human Sservices. Food and Drug Administration. Guidance for industry. Clinical trial endpoints for the approval of cancer drugs and biologics. May 2007. Available at: http://www. fda.gov/downloads/Drugs/GuidanceComplianceRegulatoryInformation/ Guidances/UCM071590. Accessed October 18, 2012

11. McKee AE, Farrell AT, Pazdur R, Woodcock J. The role of the U.S. Food and Drug Administration review process: clinical trial endpoints in oncology. Oncologist. 2010;15(Suppl 1):13-18.

12. Richey EA, Lyons EA, Nebeker JR, et al. Accelerated approval of cancer drugs: improved access to therapeutic breakthroughs or early release of unsafe and ineffective drugs? J Clin Oncol. 2009;27(26):4398-405.

13. Rajkumar SV, Gahrton G, Bergsagel PL. Approach to the treatment of multiple myeloma: a clash of philosophies. Blood. 2011;118(12):3205-11

14. U.S. Department of Health and Human Services. Food and Drug Administration. Guidance for industry. Patient-reported outcome measures: use in medical product development to support labeling claims. December 2009. Available at: http://www.ispor.org/workpaper/FDA\%20PRO\%20 Guidance.pdf. Accessed October 18, 2012.

15. Patient-Centered Outcomes Research Institute. Areas of interest for the pilot projects grants program. Available at: http://www.pcori.org/fundingopportunities/pilot-projects/areas-of-interest-for-the-pilot-projects-grantsprogram/. Accessed October 18, 2012

16. Caldwell DM, Ades AE, Higgins JPT. Simultaneous comparison of multiple treatments: combining direct and indirect evidence. BMJ. 2005;331(7521):897-900

17. Ioannidis JPA. Indirect comparisons: the mesh and mess of clinical trials. Lancet. 2006;368(9546):1470-72.

18. Sutton A, Ades AE, Cooper N, Abrams K. Use of indirect and mixed treatment comparisons for technology assessment. Pharmacoeconomics. 2008;26(9):753-67.

19. Jansen JP, Fleurence R, Devine B, et al. Interpreting indirect treatment comparisons and network meta-analysis for health-care decision making: report of the ISPOR Task Force on Indirect Treatment Comparisons Good Research Practices: part 1. Value Health. 2011;14(4):417-28.

20. Subedi P, Perfetto EM, Ali R. Something old, something new, something borrowed...comparative effectiveness research: a policy perspective. J Manag Care Pharm. 2011;17(9 Suppl A):S05-S09. Available at: http://www.amcp.org/ WorkArea/DownloadAsset.aspx?id=13711.

21. American Recovery and Reinvestment Act. The recovery act. Recovery.gov. Available at: http://www.recovery.gov/about/pages/the_act.aspx. Accessed October 18, 2012

22. Tunis SR, Benner J, McClellan M. Comparative effectiveness research: policy context, methods development and research infrastructure. Stat Med. 2010;29(19):1963-76.

23. Chalkidou K, Walley T. Using comparative effectiveness research to inform policy and practice in the UK HHS: past, present and future. Pharmacoeconomics. 2010;28(10):799-811. 
24. Song F, Altman DG, Glenny A, Deeks JJ. Validity of indirect comparison for estimating efficacy of competing interventions: empirical evidence from published meta-analyses. BMJ. 2003;326(7387):472.

25. Lu G, Ades AE. Combination of direct and indirect evidence in mixed treatment comparisons. Stat Med. 2004;23(20):3105-24.

26. Song F, Loke YK, Walsh T, et al. Methodological problems in the use of indirect comparisons for evaluating healthcare interventions: survey of published systematic reviews. BMJ. 2009;338:bl147.

27. Lumley T. Network meta-analysis for indirect treatment comparisons. Stat Med. 2002;21(16):2313-24.

28. Hoffman A, Montgomery R, Aubry W, Tunis SR. How best to engage patients, doctors, and other stakeholders in designing comparative effectiveness studies. Health Aff (Millwood). 2010;29(10):1834-41.

29. Patient-Centered Outcomes Research Institute. Patient-centered outcomes research. Available at: http://www.pcori.org/what-we-do/pcor/. Accessed October 18, 2012

30. Washington AE, Lipstein SH. The Patient-Centered Outcomes Research Institute-promoting better information, decisions, and health. N Engl J Med. 2011;365(15):e31.

31. Sanchez RJ, Mardekian J, Cziraky MJ, Mullins CD. Developing a collaborative study protocol for combining payer-specific data and clinical trials for CER. J Manag Care Pharm. 2011;17(9 Suppl A):S34-S37.

32. Atkins, D, Kupersmith J, Eisen S. The Veterans Affairs experience: comparative effectiveness research in a large health system. Health Affairs. 2010;29(10):1906-12.

33. Smith TJ, Hillner MD. Bending the cost curve in cancer. N Engl J Med. 2011;364(21):2060-65.

34. Express Scripts Research and New Solutions Lab. 2011 Drug trend report. April 2012. Available at: http://www.express-scripts.com/research/ research/dtr/archive/2012/dtrFinal.pdf. Accessed October 18, 2012.

35. Fojo T, Grady C. How much is life worth: cetuximab, nonsmall cell lung cancer, and the $\$ 440$ billion question. J Natl Cancer Inst. 2009;101(15):1044-48.

36. Hillner BE, Smith TJ. Efficacy does not necessarily translate to cost effectiveness: a case study in the challenges associated with 21 st-century cancer drug pricing. J Clin Oncol. 2009;27(13):2111-13.

37. Kenney JT. Advances in the management of multiple myeloma: implications for payors. Am Health Drug Benefit. 2011;4(2 Suppl 4):S59-S60.

38. Holcombe D. Oncology management programs for payers and physicians: evaluating current models and diagnosing successful strategies for payers and physicians. J Oncol Pract. 2011;7(3 Suppl):e46s-e49s.

39. Danielson E, Demartino J, Muller JA. Managed care \& medical oncology: the focus is on value. J Natl Compr Canc Netw. 2010;8(Suppl 7):S28-S37.

40. Henry J. Kaiser Family Foundation. Follow the pill: understanding the U.S. commercial pharmaceutical supply chain. March 2005. Available at: http://www.kff.org/rxdrugs/upload/follow-the-pill-understanding-the-us-commercial-pharmaceutical-supply-chain-report.pdf. Accessed October 18, 2012.
41. Greenapple R. Emerging trends in cancer care: health plans' and pharmacy benefit managers' perspectives on changing care models. Am Health Drug Benefit. 2012;5(4):242-53.

42 Willey VJ, Pollack MF, Lednar WM, Yang WN, Kennedy C, Lawless G. Costs of severely ill members and specialty medication use in a commercially insured population. Health Aff (Millwood). 2008;27(3):824-34.

43. Goldman DP, Joyce GF, Lawless G, et al. Benefit design and specialty drug use. Health Aff (Millwood). 2006;25(5):1319-31.

44. Taira DA, Wong KS, Frech-Tamas F, Chung RS. Copayment level and compliance with antihypertensive medication: analysis and policy implications for managed care. Am J Manag Care. 2006;12(11):678-83. Available at: http://www.ajmc.com/publications/issue/2006/2006-11-vol12-n11/Nov062388p678-683/. Accessed October 18, 2012.

45. Navarro RP, Hailey R. Overview of prescription drug benefit in managed care. In: Navarro RP, ed. Managed Care Pharmacy Practice. 2nd ed. Sudbury, MA: Jones \& Bartlett; 2009:17-50.

46. MacKinnon III GE, MacKinnon NJ. Documentation of pharmacy services. In: DiPiro JT, Talbert RL, Yee GC, Matzke GR, Wells BG, Posey LM, eds. Pharmacotherapy: A Pathophysiologic Approach. 7th ed. New York: McGrawHill; 2008:34-45.

47. Fendrick AM, Smith DG, Chernew ME. Applying value-based insurance design to low-value health services. Health Aff (Millwood). 2010;29(11):2017-21.

48. Mahoney JJ. Reducing patient drug acquisition costs can lower diabetes health claims. Am J Manag Care. 2005;11(5 Suppl):S170-S176. Available at: http://www.ajmc.com/publications/supplement/2005/2005-08-volll-n5Suppl/Aug05-2114pS170-S176/. Accessed October 18, 2012.

49. Fendrick AM. Value-based insurance design landscape digest. National Pharmaceutical Council. July 2009. Available at: http://www.sph.umich.edu/ vbidcenter/registry/pdfs/NPC_VBIDreport_7-22-09.pdf. Accessed October 18, 2012.

50. Choudhry NK, Fischer MA, Avorn J, et al. At Pitney Bowes, value-based insurance design cut copayments and increased drug adherence. Health Aff (Millwood). 2010;29(11):1995-2001.

51. Kapowich JM. Oregon's test of value-based insurance design in coverage for state workers. Health Aff (Millwood). 2010;29(11):2028-32.

52. Berwick DM. Making good on ACOs' promise-the final rule for the Medicare shared savings program. N Engl J Med. 2011;365(19):1753-56.

53. GovTrack.us. H.R. 3590 (111th) Patient Protection and Affordable Care Act. 2009. Available at: http://www.govtrack.us/congress/bills/11l/hr3590. Accessed October 18, 2012.

54. Alkeran [melphalan] package insert. GlaxoSmithKline. 2004.

55. Velcade [bortezomib] package insert. Millennium Pharmaceuticals, Inc. 2008.

56. Thalomid [thalidomide] package insert. Celgene Corporation. 2007.

57. Doxil [pegylated liposomal doxorubicin] package insert. Ortho Biotech Products, LP. 2008. 